\title{
Imagens construídas em torno da gravidez
}

\section{Mental images around pregnancy}

M aria de Fátima da Silva Vieira $M$ artins ${ }^{1}$

${ }^{1}$ Escola Superior de Enfermagem, Universidade do M inho. Largo do Paço s/ n. 4704-553 Braga Portugal.

fmartins@ese.uminho.pt
Abstract The present article is based on a study carried in six municipalities of Braga district where we performed semi-structured interviews to 100 women who had just given birth in a maternity hospital in the northern area of the country and whose residence were located in the municipalities of Amares, Braga, Póvoa de Lanhoso, Vila Verde, Vieira do M inho and Terras de Bouro. We tried to identify the representations of these women in reference to their pregnancy experience, where we point out that the origin of these representations is connected to a triangulate vision of the concept of health, illness and of the body. And all these concepts constitute extraordinarily positive aspects since some contribute towards an affectionate connection to the baby or a prenatal bond. It is important to point out that the knowledge her eby revealed is at most times a result of beliefs culturally rooted and that should beanalysed or demystified upon the prenatal surveillance consultation.

Key words Psychosocial representation, Health, Sickness, Body, Pregnancy
Resumo 0 presenteartigo surge na sequência de um estudo levado a efeito em seis concelhos do distrito de Braga, onde realizamos entrevistas semi estruturadas a cem mulheres que acabaram de dar à luz numa maternidade do norte do país e cuja residência se situa nos concelhos de Amares, Braga, Póvoa de Lanhoso, Vila Verde, Vieira do Minho e Terras de Bouro. Procuramos identificar as representações destas mulheres relativas à vivência da sua gravidez, em que salientamos que a gênesedestas representações está relacionada com uma visão triangular do conceito de saúde, de doença e do corpo e que constituem aspectos extraordinariamente positivos na medida em que al gumas contribuem para uma ligação afetiva ao bebêou vinculação pré- natal. É de salientar queo conhecimento revelado é, muitas das vezes, fruto de crenças cultural mente enraizadas e que devem ser analisadas ou desmistificadas na consulta de vigilância pré natal.

Palavras-chave Representação psicossocial, Saúde, Doença, Corpo, Gravidez 
Introdução

O conceito de representação social é um termo filosófico que significa a reprodução de uma percepção retida na lembrança ou no conteúdo do pensamento. As representações sociais, fenôme nos complexos sempre ativos na vida social, são importantes no cotidiano, uma vez que nos ajudam a definir os diferentes aspectos da realidadee permitem interpretar o que nos acontece e o que acontece à nossa volta ${ }^{1}$. Embora originário das ciências sociais, este conceito foi, pouco a pouco, inserido nos estudos da área da saúde, principalmentenaqueles que dizem respeito às concepções da população sobre o processo saúde/doença.

A gravidez pode ser considerada como uma fase de desenvolvimento em que a maternidade desempenha um papel relevante na personalidade da mulher ou, então, pode ser encarada como uma doença, podendo apresentar mudanças transitórias que conduzem à desorganizações e a reações, por vezes, patológicas².

As representações sociais constituem imagens com significados, sistemas de referência que permitem interpretar o queacontece, dando um sentido ao inesperado, categorias que servem para classificar as circunstâncias, os fenômenos ou os indivíduos com quem nos relacionamos ${ }^{3}$. É essencialmente no seio da família que as crianças aprendem um sistema de crenças, de saberes tradicionais e de representações sobre gravidez ${ }^{4}$.

\section{Material emétodos}

Tendo em conta as características do estudo que nos propomos levar a efeito, optamos por centralizar a investigação numa abordagem qualitativa, uma vez que nos interessava a globalidade dos fenômenos e a sua compreensão. Para o desenvolvimento do nosso estudo, procedemos à realização de entrevistas semiestruturadas a cem mulheres que acabaram de dar à luz na maternidade do Hospital de S. Marcos em Braga. Partindo de um intervalo de confiança de $95 \%$, realizamos uma amostra de cem mães, sendo o erro tipo de cerca de 0,049 , ou seja um erro muito reduzido em termos estatísticos, o que lhe atribui uma elevada representatividade.

Estas entrevistas foram realizadas entre fevereiro e março de 2003 e orientadas segundo um roteiro previamente concebido, que nos permitiu caracterizar socioeconomicamente as mulhe res entrevistas, bem como conhecer a história da gravidez da mulher eas representações em torno deste fenômeno. Associamos a estas a observação não participante com o objetivo de complementar alguns dos dados recolhidos. 0 registro das entrevistas foi uma atividade que não descuramos. Como suporte, podemos recorrer à memória, ao apontamento de notas ou ao gravador. Todavia, optamos pelo registro escrito dos dados obtidos e não pela gravação direta para não inibir as mães.

Tendo em conta o caráter subjetivo e particular das respostas, procedemos ao seu tratamento através da análise de conteúdo. Este tipo de análise é designado como um conjunto de técnicas deanálise das comunicações, visando obter, por procedimentos sistemáticos e objetivos de descrição do conteúdo das mensagens, indicadores (quantitativos ou não) que permitam a inferência de conhecimentos relativos às condi ções de produção/ recepção (variáveis inferidas) destas mensagens ${ }^{5}$. $N$ ão existe uma forma ideal ou mais correta de fazer análise de conteúdo; no entanto, exige-se sempre uma sistematização e coerência do esquema, tendo em consideração o objetivo do estudo. N uma das abordagens, a análise é concomitante com a recolha dos dados e fica praticamente completa no momento em que os dados são recolhidos ${ }^{6}$. $\mathrm{Na}$ nossa investigação, assumimos este tipo de abordagem, o que impõe a recolha dos dados antes de efetuar a sua análise. Contudo, sendo nós próprias a realizar as entrevistas ea transcrevê-las, foi possível efetuar alguma análise à medida que se procedia a recolha dos dados. 0 quadro teórico inicial serviu apenas de estrutura básica de apoio, uma vez que o conhecimento nunca se pode dar por concluído, estando em permanente construção. A primeira etapa consistiu na codificação dos instrumentos de recolha de dados, a que atribuímos os núme$\operatorname{ros} E_{1}$ a $E_{100}$ para as entrevistas. H ouve a necessidade de ordenar e organizar os dados de forma a conseguir transformá-los em subconjuntos. Procedemos em seguida à identificação de algumas unidades de análise? ${ }^{7}$. Ao elaborar as diferentes categorias, mantivemos, sempre que possível, as regras de análise de conteúdo com o objetivo de assegurar a sua validade. Bardin ${ }^{5}$ define algumas das qualidades das categorias:

. Homogeneidade - todas as unidades de re gistro incluídas numa categoria devem estar lógica ecoerentementeintegradas;

- Exclusão mútua - a mesma unidade de re gistro não pode ser classificada em duas categorias diferentes;

- Pertinência - adaptada ao objetivo e ao conteúdo da análise; 
- Objetividade e fidelidade - pessoas diferentes devem poder chegar a resultados iguais;

- Produtividade - um conjunto de categorias é produtivo se fornece resultados frutíferos, ou seja, dados novos e exatos.

O tema foi utilizado por nós como unidade de registro para estudar as motivações de opiniões, deatitudes e de crenças, porque permite "descobrir 'núcleos de sentido' que compõem a comunicação ecuja presença, ou frequência de aparição, podem significar alguma coisa para o objetivo analítico escolhido"5. Um segundo passo no tratamento e análise dos dados foi a identificação das subunidades de análise dentro das anteriormenteestabelecidas.

Todas as investigações constituem algum tipo de intrusão nas vidas pessoais dos indivíduos. As atividades do investigador devem ser então consideradas relativamente a um conjunto de princípios éticos e deontológicos. Dado que os nossos instrumentos estavam relacionados com aspectos pessoais, procuramos não nos interpor na intimidade das pessoas e das suas famílias mais do que o necessário para a compreensão do tema. Foram explicados às mulheres os objetivos da pesquisa, bem como a importância da confidencialidade dos dados recolhidos. Estas aceitaram participar voluntariamente do estudo após esclarecimentos aprofundados sobre 0 estudo e após ter obtido o seu consentimento informado. É evidente que só iniciamos as entrevistas após autorização da instituição envolvida.

Neste contexto, estratificamos a amostra das mulheres entrevistadas pel os seis concelhos pertencentes ao Noroeste de Portugal, sendo estes os concelhos de Amares, Braga, Póvoa de Lanhoso, Vila Verde, Vieira do M inho e Terras de Bouro, que se identificam como sendo os conceIhos de residência das mulheres entrevistadas, uma vez que consideramos a vertente territorial fundamental para o nosso estudo. A nossa opção, relativamente às entrevistas, recaiu apenas sobre as mulheres, e não sobre o casal, porque são estas que vivem a gravidez de uma forma mais intensa, é sobre estas que os conselhos das "mais velhas" semanifestam eainda porque, não obstante as facilidades que a lei faculta aos pais relativamente ao acompanhamento da gravidez, continuam a ser as mães as princi pai sfrequentadoras das consultas prénatais.

\section{Resultados: histórias da vida}

\section{Caracterização do território em estudo}

Nesta pesquisa, impressionou-nos particularmente a dimensão e a complexidade dos testemunhos revelados pelas mulheres eque demonstram uma forte ligação ao universo religioso, o que, de forma mais ao menos intensa, as influencia ao longo de toda a gravidez. Não podemos ignorar quea região em estudo se caracteriza com sendo de elevada religiosidade. Amares, situado em pleno coração do M inho, consiste numa terra de grande fervor religioso, palco de grandes festas e romarias e de grandes costumes e tradições (e.g., N ossa Senhora de A badia). Em termos econômicos, o concelho de Amares, que num passado próximo era um concelho quase exclusivamente agrícola, vê hoje desabrochar, ainda de forma tímida, uma indústria essencialmente têxtil e de construção civil, que proporciona a várias famílias a sua principal fonte de rendimento. Quanto ao concelho de Braga, podemos afirmar queconstitui, quer em termos de produção industrial, quer em termos de prestação de serviços, uma referência não só na Região N orte, como no próprio país. Outrora um concelho essencialmente agrícola, é hoje uma referência da indústria, dos serviços eatéda ciência. Bragatem sido nosúltimosanosa residência demuitosque, tendo-se deslocado para a cidade por razões acadêmicas, por aqui se fixam para sempre. Situada em pleno M inho, entre os rios Cávado e Ave, Póvoa de Lanhoso, reconhecida internacionalmente pelo seu magnífico artesanato em filigrana, tem também uma valiosa herança histórica, quer em termos de patrimônio, quer em termos de costumes e tradições. 0 seu passado predominantemente agrícola ainda hoje se faz sentir num número significativo de freguesias que 0 compõem. Vila Verde é um dos maiores e dos mais pitorescos concelhos da região do Minho. Os típicos aglomerados rurais, a gente simples e acolhedora, as magníficas casas sol arengas, os numerosos monumentos, o diversificado artesanato, a gastronomia típica, assim como as festas e romarias e os costumes e tradições são testemunho do seu importante patrimônio (e.g., N ossa Senhora do Alívio, N ossa Senhora do Bom Despacho). 
Também com um passado essencialmente agrícola, característica que ainda hoje mantém num número significativo de freguesias, conseguiu instalar indústrias noutras freguesias que constituem hojeo suporte econômico de muitos que aí residem. Localizado num território de relevo bastanteacidentado, Vieira do M inho éuma terra de muitas faces. É neste concelho que se destaca a ponte da M isarela, próxima da povoação deFrades, a cerca de um quilômetro da confluência do Cávado com o Rabagão e que, ainda hoje, é palco de cerimônias míticas relacionadas com a fertilidade das mulheres. Finalmente, Terras de Bouro é talvez o concelho menos desenvolvido de todos os que fazem parte do nosso estudo. A sua singela beleza paisagística e o seu patrimônio natural constituem uma parte significativa do Parque Natural da Peneda Gerês, e são a principal razão de um turismo cada vez mais emergente. Também as suas festividades e romarias, de que $\mathrm{S}$. Bento da Porta Aberta é 0 expoente máximo, são exemplos de um turismo religioso cada vez mais importante.

\section{Breve caracterização da amostra}

Como principais características dos elementos da amostra, podemos salientar uma elevada representatividadedemulheres residentesno concelho de Braga, com idades bastante diversificadas. Assim, verificamos queo grupo etário dos 30 aos 34 anos representa a maior percentagem da amostra, com $38 \%(n=38)$. Segue-se o grupo etário dos 25 aos 29 anos, com $29 \%(n=29)$, o dos 20 aos 24 anos, com 13\% $(n=13)$ e, finalmente, 0 grupo dos 35 aos 39 anos, com $11 \%(n=11)$. Importa ainda referir que o grupo dos 15 aos 19 anos representa $8 \%(n=8)$ da nossa amostra e que o grupo dos 40 aos 44 anos representa $1 \%$.

É de real çar, também, que a maioria dos nados-vivos nasceu no seio de uma instituição matrimonial, uma vez que $88 \%$ das mulheres eram casadas. As restantes (12\%) tiveram os seus fiIhos sem se encontrarem juridicamente casadas. Deste modo, o casamento não éaúnica forma de conjugalidade, pois outras formas, como a união defato, estão a ganhar importância, representando na amostra sete mulheres. É de salientar que $5 \%$ dosnascimentos ocorreram fora do casamento (mães solteiras), o que pode constituir um fator determinante para estas mulheres recorrerem ao apoio e conselhos da mãe, preservando comportamentos associados a tradições.

De fato, quando questionadas sobre com quem vivem, $40 \%(n=40)$ das mães afirmaram viver apenas com o "marido/companheiro", 31\% $(n=31)$ declararam viver com "marido/companheiro, com um filho ou dois filhos" e $29 \%$ das mães entrevistadas viviam com o marido, ou não, mas acompanhadas dos pais ou sogros e, por vezes, com alguns irmãos. N este contexto, é importante destacar a percentagem significativa de mães $(29 \%)$ que demonstram ter condições para serem influenciadas cotidianamente por saberes tradicionais, uma vez que vivem com familiares próximos, nomeadamente, com os pais ou com os sogros.

$66 \%$ das entrevistadas têm um nível de instrução abaixo do ensino secundário, embora também mereça destaque, pela positiva, o fato de $20 \%$ destas terem como nível de instrução o ensino superior. Ao analisarmos os dados publicados pelo INE, em $2001 \mathrm{~m}$ relativos aos nadosvivos por instrução, segundo o grupo etário da mãe, verificamosqueo número demulheres com instrução de ensino superior é de 17,9\%, percentagem esta que se aproxima significativamente da obtida na nossa amostra.

Em suma, e tendo em conta o background social, podemos considerar que estas mulheres, em termos socioeconômicos, se poderão enquadrar num estatuto médio.

\section{Análise dos relatos}

Através dos discursos proferidos pelas entrevistadas, inferimos a complexidade do conceito de representação. Organizamos a informação recolhida e, desta forma, encontramos várias representações da gravidez, como epilogamos no Quadro 1.

A primeira representação, certificada por doze mães, diz respeito à dificuldade em definir a gravidez, embora, por vezes, estas sejam acompanhadas por expressões que traduzem um sentimento de contentamento e satisfação, como podemos verificar na seguinte declaração: É uma sensação boa. Não sei como descrever (mulher de 28 anos, cuja gravidez era a segunda, com o ensino secundário e residente em Braga). Caracterizando melhor estas doze mulheres, sobressai 0 fato de dez serem multíparas, com um nível de instrução relativamentereduzido ( 1 은 clo $-n=4$; 2o e 3o ciclo - $n=3$ ) ecuja atividade profissional é, sobretudo, no setor têxtil.

A análise de conteúdo demonstrou uma nova subcategoria, a gravidez associada ao bem-estar: satisfação e realização. Esta representação foi mencionada por 47 mães e está relacionada com o conceito de saúde, definido pela OM S em 1948 
Quadro 1. Representações sobre a gravidez.

\begin{tabular}{|c|c|c|c|}
\hline Tema & Categoria & Subcategorias & $\begin{array}{l}\mathrm{N} \cong \text { de } \\
\text { referências }\end{array}$ \\
\hline \multirow{7}{*}{$\begin{array}{l}\text { A vivência } \\
\text { da gravidez }\end{array}$} & \multirow{7}{*}{$\begin{array}{l}\text { Representações } \\
\text { sobre gravidez }\end{array}$} & Dificuldade em definir & 12 \\
\hline & & Gravidez/bem-estar: satisfação e realização & 47 \\
\hline & & Gravidez/controlo do corpo & 4 \\
\hline & & Gravidez/unificação familiar e geracional & 17 \\
\hline & & Gravidez/relacionamento com o filho: encontro único & 16 \\
\hline & & Gravidez/mal-estar: doença & 4 \\
\hline & & Total & 100 \\
\hline
\end{tabular}

Fonte: Entrevistas por nós realizadas entre fevereiro e março de 2003.

como um estado de completo bem-estar, físico, mental e social enão só a ausência de doença. A gravidez é identificada como uma situação de bem-estar que pode traduzir-se num estado de equilíbrio e harmonia vivida de forma positiva e que despertará na mulher uma sensação de plenitude, de algo que fica eque a torna "mais completa". Para esclarecer este aspecto, descrevemos deseguida o relato de uma mulher de trinta anos, cuja gravidez era a primeira, com o ensino superior eresidente em Braga: É uma coisa fenomenal, quenecessita dealgum tempo de preparação. A ponta para a realização da mulher como se devesse "escrever um livro, ter um filho e plantar uma árvore". Permitiu atingir um dos meus objetivos.

A gravidez, vista como um controlo do corpo, relaciona-se com o descontrolo sobre 0 aspecto físico. Para algumas mulheres, engravidar significa deixar de ter controlo sobre o seu próprio corpo, uma vez que consideram o corpo grávido pouco atrativo, levando a que a sua imagem física fique a seus olhos, distorcida e deformada. A mulher pode ver as alterações que ocorrem no seu corpo como desmedidas. 0 lado físico da gravidez pode aparecer como o lado estranho, desconfortável e indesejável. Vejamos uma de quatro narrativas, referidas por quatro das mulheres entrevistadas, residentes em áreas predominantemente urbanas ${ }^{8}$, com uma média de idade de 29 anos, que planearam a sua gravidez e com o grau de instrução bastante elevado ( $n=3$ com ensino superior): Representou várias sensações. Por um lado, gostei de sentir o bebêdentro de mim, por outro não gostei de sentir as alterações no meu corpo, nem dos desconfortos provocados pela barriga a crescer. $N$ ão gostei de vestir a roupa de grávida, nem de mostrar a barriga. A minha imagem corporal foi-se alterando e isto me incomodou. Esta gravidez foi só para ter um filho (muIher de 27 anos, cuja gravidez era a primeira, com 0 ensino superior e residente em Braga).

Verificamos que estes testemunhos de desagrado relativamente às alterações físicas provocadas pela gravidez advêm de mães com instrução ao nível do ensino superior. Podemos então colocar a seguinte questão: haverá alguma explicação para que estas sensações de desconforto e de desagrado pela própria imagem tenham particular repercussão em mães com um nível de instrução mais elevado? 0 estudo que levamos a efeito não procurou qual quer explicação para este fato; por isso, qualquer consideração que a seguir possamos tecer não assenta na informação recolhida. Contudo, é nossa convicção que as grávidas com maior nível de instrução provavelmente seencontrarão num status social mais elevado, em que a cultura da imagem corporal segundo padrões de beleza ester eotipados está mais enraizada. Qualquer alteração (aumento de peso e consequente alteração da "linha", limitação da mobilidade e da agilidade) que possa constituir um desvio ao estereótipo interiorizado vai traduzir-se em manifestações de desagrado como as que acima se transcreveram.

Associada a esta representação, a gravidez é considerada como mal-estar sinônimo de doença. Esta idéia está em contradição com a subcategoria relacionada com o bem-estar. As complicações, as alterações e a história de gravidezes anteriores, cujo desenvolvimento culminou em abor- 
tamento, fazem com que estas considerem a gravidez como algo deestranho, desconfortante de mal-estar. Contudo, apenas quatro mulheres descrevem estefato, sendo mulheres mais vel has com uma idade superior a trinta e quatro anos (ape nas uma tem dezoito anos), duas multíparas que já tiveram uma história de abortamento em gravidezes anteriores e duas primigestas. É de salientar que apenas uma das multíparas (quarta gravidez) não a planeou. 0 nível de instrução destas grávidas é razoável, tendo a maioria $(n=3)$ um nível de instrução correspondente ao 30 ciclo do ensino básico e uma ao ensino superior, vivendo todas em áreas mediamente urbanas.

Todavia, a gravidez associada à unificação familiar egeracional foi citada por dezessetemães. A maioria destas mulheres, com idades entre os 20-24 anos $(n=6)$ e 30-34 anos $(n=6)$, residem em áreas mediamente urbanas ${ }^{8}(n=11)$, têm como grau de instrução o $2^{\circ}$ ou $3^{\circ}$ ciclo do ensino básico e encontram-se grávidas pela primeira $(n=8)$ ou segunda vez $(n=9)$.

A gravidez permite não só a continuidade da família, bem como a transmissão de diferentes heranças. Ter um filho significa, sem dúvida, perpetuar-se, para transmitir a outro o seu destino. É nestes termos que as mães aludem: É uma coisa muito importante. Quando soube, nem parecia verdade. É uma coisa nossa, um pedacinho denós. Estar grávida permite a continuidade da família. Vai ser uma companhia para o resto da minha vida (mulher de 28 anos, cuja gravidez era a primeira, com o ensino superior e residente em Amares).

Neste contexto particular, a gravidez/relacionamento com o filho - encontro único foi também uma das representações da gravidez descritas por dezesseis mulheres, em que apenas onze planearam a sua gravidez. Assim, nove estavam grávidas pela segunda vez, seis pela primeira e apenas uma pela terceira vez.

Importa ainda assinalar que estas narrativas dizem respeito a mulheres com idades compreendidas entre os 20 e 34 anos, havendo uma maior frequência para as mulheres com 30-34 anos que residem em áreas predominantemente urbanas $(n=10)$ e em áreas mediamente urbanas $(n=5)$. A penas uma mulher vive numa área predominantemente rural. Q uanto ao nível de instrução, comprovamos que seis mulheres apre sentam uma instrução ao nível do 2 o ciclo do ensino básico, o que se afigura como relativamente baixo, referindo quatro mulheres o nível deensino secundário. Nenhuma referiu ter como nível de instrução o ensino superior.
Estes relatos demonstram como é possível viver uma relação desimbioseentrea mãe/grávidae o filho/feto. É uma relação única ecompleta, em que a mãe se relaciona com o seu filho como fazendo parte de si própria. Para estas mulheres, o feto é capaz de interagir com elas. A nossa experiência profissional mostra-nos que estes fatos são aspectos extraordinariamente positivos, na medida em que contribuem para o reforço da vinculação.

\section{Consideraçõesfinais}

Em jeito de conclusão, podemos afirmar que, no estudo levado a cabo, em consonância com as considerações abordadas pelos diferentes autores, as grávidas admitem "a imagem da gravidez" como uma imagem multifacetada, o que talvez esteja relacionado com questões individuais, familiares, culturais e sociais. Podemos caracterizar as mulheres queidentificam a gravidez como uma doença por serem ligeiramente mais "velhas" (média de idades de 34 anos), por residirem também em áreas mediamente urbanas, mas com um grau de instrução bastante elevado, demonstrando terem uma história obstétrica com complicações.

$\mathrm{N}$ o que diz respeito às mulheres para quem a gravidez representa uma situação de bem-estar e sati sfação, verificamos que é transversal a toda a amostra, quer quanto ao número de gravidezes, quer quanto ao nível de instrução ou área de residência. A gravidez é designada como algo de positivo. Esta é contemplada como um sonho, que nasce, muitas das vezes, antes de nascer no plano obstétrico. Estas opiniões dizem respeito a grávidas que planearam a sua gravidez e que a aceitaram sem qualquer dificuldade. 0 fato de, por vezes, estas gravidezes não serem planeadas não interferiu com a sua realização e satisfação. M esmo no caso das mães adolescentes e multíparas, na sua maioria, também viveram a gravidez de forma positiva.

Constatamosainda quea mulher évista como um agente de saúde primário, que assume a responsabilidade decuidar do seu filho enquanto se encontra no ventre, daí muitas das vezes aderirem ao conteúdo de mitos e de crenças como, por exemplo, não deves comer laranjas porqueo bebe nasce amarelo, mas também de cuidar do futuro deste através do alimentar, do vestir, de proteger, ou seja, está relacionada com a função protetora e econômica da família. N este estudo, 
apuramos ainda que $82 \%$ alteraram os seus comportamentos cumprindo assim as crenças e mitos porque "mais vale prevenir do que remediar" ou "mesmo quando não se acredita, faz-se, porque senão faz bem, mal também não devefazer". Estes aspectos afiguram-se como determinantes para quem investiga a área de saúde materna e infantil e desempenha funções no âmbito da vigilância de saúde prénatal.

Estas representações não podem ser vistas como desarticuladas do contexto de vida decada mulher. Verificamos ainda que a gravidez eo ato deser mãe setornam cada vez mais significativos para um maior número de mulheres. Cada vez mais se aponta a gravidez como um projeto de vida ou como forma de reforçar o casamento. Contudo, a gravidez associada ao nascimento e à maternidade, parte, por vezes, de um imaginário impregnado pelo medo de deformação deum corpo como se de uma doença se tratasse. Como passar da imagem mulher/grávida/mãe no imaginário coletivo para essas figuras atuais de muIheres grávidas com o corpo esbelto, figura que hoje está presente e usada no marketing social? "Ora, esta é a questão fulcral com que nos debatemos hoje: a de pensar o corpo e o pensamento sem desvalorizar um sobre o outro, sem barrar o conhecimento de um e do outro" .

\section{Referências}

1. Jodelet D. Les représentations sociales. Paris: Presses Universitaires de France; 1999.

2. Canavarro MC. Psicologia da gravidez e maternidade. Coimbra: Quarteto Editora; 2001.

3. Duarte S. Saberes de saúde e de doença: Porque vão as pessoas ao médico. Coimbra: Quarteto; 2002.

4. Leandro ME. Sociologia da família nas sociedades contemporâneas. Lisboa: Universidade Aberta; 2001.

5. Bardin L. Análise de conteúdo. Lisboa: Ed. 70; 1995.

6. Bogdan R, Biklen S. Investigação qualitativa em educação - uma introdução à teoria e aos métodos. Porto: Porto Editora; 1994.

7. Goetz JP, Le Compte M D. Etnografía y diseño cualitativo en investigación educativa. M adrid: M orata; 1988.

8. Instituto Nacional de Estatística. Direção Geral do Ordenamento do Território e Desenvolvimento Urbano. Indicadores urbanos do continente. Série de Estudos no 80. Lisboa: Instituto Nacional de Estatística; 1999.

9. Joaquim T. A questão da maternidade e o imaginário coletivo. In: Comissão para a Igualdade e para os Direitos das Mulheres. Maternidade: mitos e realidades. Lisboa: Coleção Cadernos Condição Feminina; 1992. p. 36-47.

Artigo apresentado em 20/09/2007

Aprovado em 27/06/2008

Versão final apresentada em 10/09/2008 